ojs.uv.es/index.php/qfilologia/index

Rebut: 30.06.2020. Acceptat: 27.07.2020

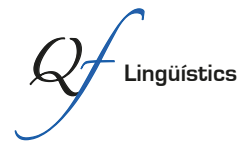

Per a citar aquest article: Fidalgo Enríquez, Francisco José. 2020. "La eclosión de irei+infinitivo como expresión de la futuridad en portugués”. Quaderns de Filologia: Estudis Lingüístics XXV: 57-73.

doi: $10.7203 /$ QF.25.19069

\title{
La eclosión de irei+infinitivo como expresión de la futuridad en portugués
}

\author{
The emergence of irei+infinitivo as an expression of the futurity in Portuguese
}

\author{
Francisco José Fidalgo EnRÍQuez \\ Universidade de Aveiro \\ fjfe@ua.pt
}

Resumen: La perífrasis ir+infinitivo ha reemplazado al futuro sintético -rei con el valor temporal de futuridad en la lengua oral del portugués en todas sus variedades diatópicas y en casi todos los registros, excepto en el registro más culto, y en la lengua escrita en registros no cultos conforme a un proceso de gramaticalización común a varias lenguas. En todas las variedades del portugués actual ha emergido en el siglo pasado la perífrasis irei+infinitivo con el verbo auxiliar en el futuro. El propósito de este artículo es estudiar los valores modo-temporales de esta construcción que presuponen un grado más en la gramaticalización de ir+infinitivo. Para lograr nuestros objetivos, realizamos un breve análisis sincrónico y diacrónico de casos relevantes con base en corpora de referencia.

Palabras clave: Futuridad; portugués; perífrasis; futuro sintético; futuro analítico.

\begin{abstract}
The periphrasis ir+infinitive has replaced the synthetic future - I laugh with the temporal value of futurity in the oral language of Portuguese in all its diatopic varieties and in almost all registers, except in the most cultured register, and in the written language in registers not cultured according to a grammaticalization process common to several languages. In all the varieties of current portuguese the irei + infinitive periphrasis with the auxiliary verb in the future has emerged in the last century. The purpose of this article is to study the mode-temporal values of this construction that presuppose a further degree in the grammaticalization of ir + infinitive. To achieve our objectives, we carry out a brief synchronous and diachronic analysis of relevant occurrences based on reference corpora.
\end{abstract}

Keywords: Futurity; portuguese; periphrasis; grammaticalization; synthetic future; analytical future. 


\section{Introducción}

Esta perífrasis del portugués formada con el verbo ir (futuro)+infinitivo irei+infinitivo es una de las expresiones de la futuridad más singulares del portugués y del ámbito romance. Dos santos (2004) y Santos (1997) denominan a esta forma "futuro sintético perifrástico" . Curiosa definición pero cercana a su valor, porque es un futuro analítico irei amar 'disfrazado' de sintético, por el uso del futuro simple en el auxiliar, y con funciones parecidas a las del futuro morfológico amarei, pero con valores añadidos propios del futuro perifrástico ir+amar.

Pese a ser citada por muchos autores como una forma de expresión de la futuridad en el Portugués de Brasil (PB) (Tafner 2004; Dos Santos 2004; Oliveira 2006; Oliveira \& Olinda 2008; Poplack \& Malvar 2007; Barbosa 2007; Thomas I969 o Longo I998), ninguno de ellos ${ }^{2}$ explica sus valores, definiéndola apenas como una variedad contextual de la perífrasis ir+infinitivo.

Con relación al Portugués Europeo (PE), en las obras que hemos consultado -Vilela (I999); Oliveira (I985); Mateus, Brito, Duarte, Hub Faria, Frota, Matos, Oliveira, Vigário \& Villalva (2003); Cunha \& Cintra (I984); Barroso (I994), Raposo, Bacelar do Nascimento, Da Mota, Segura \& Mendes (2013)irei+infinitivo ni siquiera aparece entre las formas que expresan futuridad. Pese a no figurar en estas obras de referencia, es sencillo hallarla tanto en textos de la variedad europea como de la variedad americana, indicando así que esta forma tiene vigencia y vitalidad. Sin embargo, no existe, a fecha de hoy ${ }^{3}$, un estudio monográfico de amplio calado excepto el que hemos acometido. Son muchos los trabajos que se han dedicado a encontrar y explicar las diferencias entre el futuro sintético: amarei y el perifrástico: ir+infinitivo, pero nadie parece haber decidido que una forma sintética y perifrástica merece atención particular.

\section{Valores temporales}

Thomas (1969:123), en su libro The syntax of spoken Brazilian Portuguese, señala sobre esta forma:

\footnotetext{
I “(I) F.S.P. -futuro sintético perifrástico (-irei + v) - “Caríssima secretária, tendo em vista a sua falta de tempo, irei ajudá-la” (Dos Santos 2004:7).

${ }^{2}$ No deja de ser chocante que ningún autor portugués haga alusión explícitamente a esta forma.

${ }^{3}$ Incluyendo el capítulo 5.4.3.4. en Fidalgo 2012.
} 
Esta construção não é muito freqüente, mas é recorrente na fala o suficiente para ser considerada uma forma estabelecida. É usada na escrita menos formal, como revistas, mas é rara na literatura.

A nuestro modo de ver, desde la concepción de este libro, esta forma ha crecido mucho en uso y no es exclusiva solo de las revistas ni del PB. Aunque coincidimos con Thomas en que, a falta de un estudio integral y científico exclusivo, es más usual en textos escritos no demasiado formales (vid. infra 4).

Santos (1997: 13) da cabida a esta forma entre las que expresan futuridad y señala que tiene características de la forma perifrástica vou+infinitivo y del futuro sintético amarei:

A soma das marcas das duas formas de futuro garante a dupla realização morfêmica de futuro: tem-se a futuridade expressa pelo verbo ir de movimento, e também o morfema de futuro simples no próprio ir .

De esta definición nos gustaría saber a qué se refiere con la doble "realização morfêmica de futuro" más allá de la evidencia formal. Hablar de una doble futuridad parece una redundancia innecesaria. ¿Se puede establecer que irei amar expresa lo mismo que la forma sintética amarei? ¿Son expresiones de futuridad diferentes? Una de las soluciones que se ha propuesto es que esta perífrasis irei amar expresa un futuro posterior a otro futuro. Esta propuesta de Bechara (I999: 285) para el portugués ha sido rechazada porque, aunque es una posibilidad del sistema verbal, puesto que existen formas propias en portugués para expresar un futuro anterior a otro futuro (futuro de ter + participio), y podría existir, asimismo, una forma para un contenido hipotético de futuro posterior a otro futuro. Los hablantes del portugués, por ahora, no han considerado que para la expresión de tal contenido (futuro posterior a otro futuro) sea necesario cifrar morfológicamente una determinada forma verbal sintética o perifrástica. Esa posibilidad existe, ese contenido existe, pero la forma irei+fazer no es la manera de reflejarlo y además existen otros cauces de expresión (I):

(I) Amanhã vou falar com o Carlos.

(2) Amanhã irei falar com o Carlos.

La diferencia entre (I) y (2) no radica en que la forma de (2) indique futuro posterior a otro futuro por sí sola, ya que ambas expresan solo futuridad, esto es, un futuro posterior al Momento de la Enunciación (ME). El contenido de 
futuro posterior a otro futuro es expresable únicamente por medios contextuales no morfológicos, no mediante formas verbales concretas, por lo que ambas formas, en contextos propicios (3) y (4), pueden indicar ese valor:

(3) Amanhã vou falar com o Carlos, depois de ter com o Luís.

(4) Amanha irei falar com o Carlos, depois de ter com o Luís.

Así pues, esta forma expresa futuridad con respecto al $\mathrm{ME}^{4}$, tal como el futuro sintético, no futuridad con respecto a otro futuro, y a diferencia de la perífrasis vou+infinitivo, irei+infinitivo parece expresar solo futuridad sin conexión con el ME. Se desecharía así la teoría de Bauhr (I989) del Rasgo de Relevancia Actual (RRA) como elemento configurador radical de toda la perífrasis ir a+infinitivo, tesis seguida por Santos (I997) y por Longo (I998) para el portugués ir+infinitivo. Recordemos que el RRA supone que:

El valor básico del futuro en -ré es la indicación de una relación de posterioridad al origen $(\mathrm{O}+\mathrm{V})$, mientras que el de ir a+infinitivo es la indicación de una relación de posterioridad a la situación simultánea al origen $((\mathrm{OoV})+\mathrm{V})($ Bauhr 1989:32).

No obstante, la descripción, en términos temporales, que mejor se acomoda a la perífrasis irei+infinitivo, no es $((\mathrm{OoV})+\mathrm{V})$, como defiende Bauhr, siendo simultánea con el ME (OoV), ni tampoco la de Bechara (i999) $((\mathrm{O}+\mathrm{V})+\mathrm{V})$, sino la de posterior al origen $(\mathrm{O}+\mathrm{V})$ como el futuro sintético amarei. En consecuencia, parece que bajo el prisma de la teoría del RRA no puede explicarse la diferencia entre estas dos formas del portugués: irei amar/amarei, dado que irei amar no es ni $((\mathrm{OoV})+\mathrm{V})$ ni $((\mathrm{O}+\mathrm{V})+\mathrm{V})$, sino exclusivamente $(\mathrm{O}+\mathrm{V})$.

Según Bauhr (I989), la diferencia entre el futuro $(\mathrm{O}+\mathrm{V})$ y la perífrasis voy a+infinitivo $(\mathrm{OoV})+\mathrm{V}$ radica en la simultaneidad de esta última con el punto de origen. Si aplicamos estos mismos criterios a irei amar, llegaríamos a las mismas conclusiones que Bechara (I999). La forma perifrástica irei amar sería $(\mathrm{O}+\mathrm{V})+\mathrm{V}$, indicando posterioridad al origen y posterioridad a otro punto $(\mathrm{O}+\mathrm{V})$. Sería, pues, futuro posterior a otro futuro. Si nos fijamos en los siguientes ejemplos:

(5) As jornadas irão decorrer na próxima quinta-feira.

(6) As jornadas decorrerão na próxima quinta-feira.

${ }_{4}^{4} \mathrm{Tal}$ como el presente de indicativo o la perífrasis haver de+infinitivo. 
No parece que (5) exprese un futuro posterior a otro futuro. Si nos atenemos al criterio del RRA, ¿podríamos afirmar que (6) tiene conexión con el presente como la forma perifrástica (7) con el auxiliar en presente $v \widetilde{a} o$ ?

(7) As jornadas vão decorrer na próxima quinta-feira.

Ni siquiera parece que el RRA sea un criterio válido para las construcciones con vou+infinitivo. Es verdad que podemos hablar de un futuro más inmediato con la perífrasis vou+infinitivo que con irei+infinitivo o amarei, pero siempre que no haya otros elementos contextuales que determinen la distancia temporal. En ese caso, estas diferencias temporales parecen neutralizarse como en (5), (6) y (7). A nuestro modo de ver, no podemos diferenciar irei amar y amarei atendiendo a criterios estrictamente temporales como el de conexión con un momento temporal simultáneo al presente o como los conceptos temporales de proximidad o lejanía temporal al ME.

\section{Valores aspectuales y modales}

En lugar de intentar definir la forma ir+infinitivo en términos temporales, se puede intentar definirla aspectualmente. Este enfoque no parece que sea plausible para muchos estudiosos en el PB, pues solo Tafner (2004) y Oliveira (2006) adoptan los valores aspectuales para esta forma y llegan a la conclusión de que, en la actualidad, irei+infinitivo no posee tales valores. Los estudios diacrónicos consultados por nosotros, a excepción de Poplack \& Malvar (2007), si bien mencionan tangencialmente que los primeros valores de esta perífrasis eran aspectuales incoativos y precedían a los temporales de futuridad inmediata, obvian la importancia de este contenido aspectual para la definición de ir+infinitivo. En portugués de Portugal, entre los pocos estudiosos que aluden a la funcionalidad de contenido aspectual destacamos a Barroso (I994), que sí proclama el valor aspectual incoativo de esta perífrasis, a Vilela (1999), a Cunha \& Cintra (I984), a Vázquez Cuesta \& Mendes da Luz (I97I) o a Oliveira (i985), que, si bien no explícitamente, sí tácitamente aceptan este contenido aspectual. Pese a la exigüidad de argumentos de autoridad en la literatura científica al respecto, creemos que los valores aspectuales sí son un elemento constitutivo de esta forma analítica ir+infinitivo en portugués como lo son de la del español ir a+infinitivo, ya que ambas perífrasis son expresión del valor aspectual prospectivo. Este valor aspectual prospectivo supone la relación topológica entre dos tiempos; el tiempo total de la situación (TS) y del 
tiempo de foco (TF). El tiempo de foco se refiere a una situación anterior a la del TS y no se incluye en él, pero influye en el tiempo de situación que es, por su parte, posterior (Klein I994). En la perífrasis ir+infinitivo con el auxiliar en presente vou+infinitivo, el tiempo de la situación (TS) sería el resultado de analizar en conjunto toda la forma perifrástica, siendo el tiempo de foco, parte del tiempo de situación. Además, como característica peculiar, el evento o acción expresada por esta perífrasis estaría conectado con un estado de cosas anterior, no posterior, deviniendo en un valor integral aspectual, pero no temporal. Así, la conexión aspectual entre el tiempo de foco y el tiempo de situación tendría una base aspectual y el contenido temporal que deviene de ella, el de futuro, sería originado en esta relación aspectual de prospectividad. Esta relación de prospectividad tendría varias fases aspectuales, figurando dentro de ella la ingresiva o incoativa y varias formas de expresión temporal, dependiendo de a qué momento temporal se refiera el auxiliar, presente: vou+infinitivo o pasado: ia+infinitivo (Bravo 2008).

Esta teoría, plausible y sugerente, se encuentra con varios problemas en la aplicación al portugués. El primero de ellos es que hay formas perifrásticas vou+infinitivo que no tienen ningún valor aspectual, sobretodo en portugués de Brasil, por lo que pueden sustituir perfectamente a las formas sintéticas amarei y funcionar, como ellas, solo con valor de futuridad y, por consiguiente, sin valor aspectual. En segundo lugar, la forma irei+amar del portugués, tanto americano como europeo, desestructura todas las bases de la concepción lingüística aspectual citada, si es que podemos aceptar este valor aspectual como base exegética, puesto que el tiempo de foco, expresado en el verbo auxiliar, ya no es un tiempo anterior al tiempo de situación sino que ambos son futuros, es decir, el auxiliar está en futuro (irei), que sería el tiempo de foco (TF), y toda la perífrasis (irei+amar), que sería el tiempo de situación (TS), también indica futuridad. Además, el tiempo de situación como el tiempo de foco no se excluyen, es decir, no existe un futuro posterior a otro futuro, ni un futuro anterior a otros, sino que son simultáneos. Quizás, esta perífrasis no exprese ya aspectualidad sino tan solo futuridad.

La pérdida del valor aspectual de la perífrasis irei+infinitivo es una muestra de que esta forma se encontraría en la última fase del proceso de gramaticalización, aunque es verdad que el proceso no habría finalizado, dado que conserva valores modales. Según las cadenas evolutivas de gramaticalización de la futuridad de Bybbe et alii (I994), de Heine et alii (I99I), de Fleischman (I982) o la propuesta de evolución diacrónica de ir a+infinitivo de Melis (2006), después de haber perdido los valores aspectuales las formas que 
expresan futuridad solo pueden tener contenidos temporales y modales. La existencia y empleo vital de la forma irei amar en el portugués indicaría que la perífrasis ir+infinitivo está en un estado de gramaticalización muy avanzado debido a que, en muchos contextos, ha perdido el valor aspectual prospectivo, manteniendo solo valor temporal. La irrupción del futuro en el auxiliar sería posible solo si el valor aspectual prospectivo hubiese dejado de ser un elemento definidor radical, como así parece ser en este caso, pero no en todos los casos.

Al perder el punto de conexión aspectual con un momento anterior al expresado por la perífrasis, sea coincidente con el ME o con un punto anterior a éste, vou+infinitivo sirve para expresar todo tipo de futuridad (inmediata y mediata) e irei+infinitivo tiene solo valor temporal, exactamente el mismo que la forma sintética amarei. Es decir, la forma vou+infinitivo sería usada para la expresión de la futuridad cercana cuando el contexto no sea determinante y para la expresión de la futuridad inmediata y mediata en el resto; la forma sintética amarei como la forma analítica irei+infinitivo servirían siempre para la expresión de la futuridad mediata y en algunos contextos propicios podrían oponerse a la forma vou+infinitivo que expresaría una futuridad no mediata o cercana. De esta manera, la forma vou+infinitivo puede dar cabida a esta futuridad inmediata relacionada con el valor aspectual incoativo o inminencial, porque todavía posee algunos valores aspectuales prospectivos en determinados contextos. La forma irei+infinitivo no tiene valor aspectual alguno, por lo que no puede expresar esta futuridad inmediata, aunque sí podría expresar futuridad cercana en contextos adecuados.

En consecuencia, las formas perifrásticas vou+infinitivo/irei+infinitivo se distinguirían conforme al rasgo +/- aspectual de la forma vou+infinitivo y la consiguiente posibilidad de expresar también futuridad inmediata. Para distinguir la forma amarei de la forma irei+infinitivo solo podemos acudir a los valores modales. Estos son los únicos valores que resultan pertinentes para distinguir ambas formas. Los asociados a la forma irei+infinitivo están relacionados con su condición de perífrasis y su menor estado de gramaticalización, siendo los valores modales propios de esta forma un contenido epistémico de alto compromiso con la acción futura por parte del hablante, sobre todo en las primeras personas, y un contenido intencional. La forma sintética amarei que en portugués está casi en la última fase de la gramaticalización, tiene valores epistémicos de probabilidad, posibilidad, de cortesía, de atenuación y valores deónticos. La forma analítica irei+infinitivo añade unos valores modales de intención y compromiso del hablante con la acción futura, que no tiene la forma 
sintética y que distinguen a ambas. No obstante, en el PB la forma perifrástica está perdiendo los valores modales de intención o de compromiso elevado del hablante con la acción por valores de probabilidad.

\section{Datos de corpora}

Hemos realizado una búsqueda en el corpus Davies-Ferreira (2006)5 de la perífrasis ir(futuro)+infinitivo (Ir+ infinitivo IR_VF VR- $)^{6}$, estando el resultado patente en esta tabla:

\begin{tabular}{|c|c|c|c|c|c|c|c|c|c|c|c|c|c|c|c|}
\hline SEÇÃO & TODOS & $\begin{array}{l}S . \\
13\end{array}$ & $\begin{array}{l}\text { S. } \\
14\end{array}$ & $\begin{array}{l}S . \\
15\end{array}$ & $\begin{array}{l}S . \\
16\end{array}$ & $\begin{array}{l}S . \\
17\end{array}$ & $\begin{array}{l}\text { S. } \\
18\end{array}$ & $\begin{array}{l}S . \\
19\end{array}$ & $\begin{array}{l}S . \\
20\end{array}$ & PORT & BRAS & $A C D$ & NOT & FIC & ORA \\
\hline FREQ & 4767 & 5 & 5 & 5 & 42 & 19 & 3 & 272 & 1472 & 888 & 584 & 249 & 932 & 127 & 164 \\
\hline $\begin{array}{l}\text { TAMAN- } \\
\mathrm{HO}\end{array}$ & 45 & 0.6 & 1.3 & 2.8 & 4.3 & 3.3 & 2.2 & 9.7 & 20.3 & 10.2 & 10.0 & 5.8 & 6.5 & 5.9 & 2.1 \\
\hline $\begin{array}{l}\text { POR } \\
\text { MILHÃO }\end{array}$ & 105.93 & 9.07 & 3.88 & 1.76 & 9.69 & 5.81 & 1.37 & 27.94 & 72.64 & 86.93 & 58.12 & 43.27 & 143.63 & 21.39 & 78.72 \\
\hline
\end{tabular}

Podemos apreciar que irei+infinitivo crece a partir del s. xx, aunque hay un número de ejemplos significativo en el s. xix. También se puede verificar que se datan más casos en Portugal que en Brasil. Solo tenemos ejemplos en los diversos tipos de textos en Portugal y Brasil en el s. xx que se reflejan en la tabla anterior en las últimas cuatro columnas. Ahí, podemos comprobar que la construcción analítica predomina en periódicos y revistas y en los textos orales. En los textos académicos y ficcionales, el futuro simple -rei aún es una forma bastante usada. Si comparamos los datos de irei+amar en ambos países por textos7 , cabe destacar el empleo preeminente, en los dos países, en los textos periodísticos y la preferencia en los textos orales tanto en Portugal como en Brasil, porque en ambos países se emplea raramente amarei en los

\footnotetext{
${ }^{5}$ Este corpus consta de más de 45 millones de palabras que provienen de poco menos de 57.000 textos. Tiene 20 millones de palabras del siglo xx, io millones del siglo xix y I5 millones de palabras de los siglos xiII al xvin. Del siglo xx, el corpus contiene seis millones de palabras de ficción, seis millones de periódicos y revistas, seis millones de textos académicos y dos millones de textos orales. Los textos del siglo xx se dividen en partes iguales entre textos de Portugal y Brasil.

${ }^{6}$ Lema de la búsqueda en los corpora. Hemos incluido el lema en cada búsqueda realizada.

7 Brasil> Académico I70 / Notícias 300 / Ficção 65 / Oral 49.

Portugal> Académico 79 / Notícias 632 / Ficção 62 / Oral II5.
} 
textos orales, excepto en registros cultos y formales. Incluso, la utilización de amarei en el ámbito académico en Brasil (37\%) es menor que en el PE (63\%).

Hemos realizado también una búsqueda en el corpus del portugués NOW (News On Web) que contiene I,4 millones de palabras de periódicos y revistas en línea desde el 20I2 hasta el primer semestre de 20I9. De la búsqueda del lema ir(futuro)+infinitivo (IR_vif\% VERB) hemos recogido los siguientes datos:

\begin{tabular}{|c|c|c|c|}
\hline SEÇÃO & FREQ & TAMANHO & POR MILHÃO \\
\hline $2012-1$ & 2.498 & 17.7 & 141.20 \\
\hline $2012-2$ & 2.758 & 19.7 & 139.82 \\
\hline $2013-1$ & 8.127 & 55.3 & 146.87 \\
\hline $2013-2$ & 8.346 & 60.1 & 138.95 \\
\hline $2014-1$ & 10.028 & 62.0 & 161.64 \\
\hline $2014-2$ & 10.333 & 65.7 & 157.36 \\
\hline $2015-1$ & 11.821 & 72.0 & 164.16 \\
\hline $2015-2$ & 13.123 & 76.0 & 172.62 \\
\hline $2016-1$ & 12.143 & 73.7 & 164.87 \\
\hline $2016-2$ & 16.086 & 96.5 & 166.67 \\
\hline $2017-1$ & 27.290 & 166.8 & 163.61 \\
\hline $2017-2$ & 25.405 & 165.2 & 153.78 \\
\hline $2018-1$ & 22.512 & 146.1 & 154.09 \\
\hline $2018-2$ & 29.169 & 167.0 & 174.69 \\
\hline $2019-1$ & 32.027 & 199.3 & 160.73 \\
\hline TOTAL & 231.666 & & \\
\hline & & & \\
\hline
\end{tabular}

Como podemos apreciar el número de casos de irei+infinitivo en apenas ocho años es bastante superior a los contenidos en el anterior corpus. Hay que tener en cuenta que el tipo de texto analizado, periódicos y revistas, es el más propicio a la aparición de esta perífrasis.

En los datos por países destaca que la frecuencia es similar en Portugal y Brasil, aunque el número de casos por millón es mucho más destacable en Portugal. 


\begin{tabular}{|c|c|c|c|}
\hline SEÇÃO & FREQ & TAMANHO & POR MILHÃO \\
\hline Brasil & 118439 & 836.1 & 141.66 \\
\hline Portugal & 111705 & 339.4 & 329.10 \\
\hline Angola & 974 & 15.3 & 63.47 \\
\hline Moçambique & 548 & 3.5 & 155.35 \\
\hline
\end{tabular}

En los países sobre los que tenemos datos, podemos comprobar en las siguientes tablas que en todos ellos la forma irei+infinitivo crece en empleo, aunque en el caso de Brasil crecen los casos, pero disminuye el porcentaje por millón. En Portugal, los ejemplos aumentan así como el porcentaje por millón. Tanto en Angola como en Mozambique es una forma residual porque nunca llega a superar el $2 \%$ por millón y los doscientos casos por semestre ${ }^{8}$, aunque el número total de formas es escaso para ser relevante en el estudio.

\section{Brasil}

\begin{tabular}{|c|c|c|c|}
\hline SEÇÃO & FREQ & TAMANHO & POR MILHÃO \\
\hline $2012-1$ & 1.779 & 17.7 & 100.56 \\
\hline $2012-2$ & 1.963 & 19.7 & 99.52 \\
\hline $2013-1$ & 6.697 & 55.3 & 121.03 \\
\hline $2013-2$ & 6.845 & 60.1 & 113.96 \\
\hline $2014-1$ & 7.328 & 62.0 & 118.12 \\
\hline $2014-2$ & 6.784 & 65.7 & 103.31 \\
\hline $2015-1$ & 6.920 & 72.0 & 96.10 \\
\hline $2015-2$ & 7.317 & 76.0 & 96.25 \\
\hline $2016-1$ & 6.225 & 73.7 & 84.52 \\
\hline $2016-2$ & 8.017 & 96.5 & 83.06 \\
\hline $2017-1$ & 12.077 & 166.8 & 72.40 \\
\hline $2017-2$ & 12.140 & 165.2 & 73.48 \\
\hline $2018-1$ & 10.396 & 146.1 & 71.16 \\
\hline $2018-2$ & 11.011 & 167.0 & 65.94 \\
\hline $2019-1$ & 12.940 & 199.3 & 64.94 \\
\hline TOTAL & 118.439 & & \\
\hline
\end{tabular}

\footnotetext{
${ }^{8}$ No hemos incluido los datos pormenorizados por cada semestre por falta de espacio en este artículo. De la misma manera, no han sido incluidos los datos referentes al futuro simple amarei o a la perífrasis ir(presente)+infinitivo por la misma causa.
} 


\section{Portugal}

\begin{tabular}{|c|c|c|c|}
\hline SEÇÃO & FREQ & TAMANHO & POR MILHÃO \\
\hline $2012-1$ & 687 & 17.7 & 38.83 \\
\hline $2012-2$ & 741 & 19.7 & 37.57 \\
\hline $2013-1$ & 1.381 & 55.3 & 24.96 \\
\hline $2013-2$ & 1.436 & 60.1 & 23.91 \\
\hline $2014-1$ & 2.654 & 62.0 & 42.78 \\
\hline $2014-2$ & 3.480 & 65.7 & 52.99 \\
\hline $2015-1$ & 4.818 & 72.0 & 66.91 \\
\hline $2015-2$ & 5.731 & 76.0 & 75.39 \\
\hline $2016-1$ & 5.816 & 73.7 & 78.97 \\
\hline $2016-2$ & 7.955 & 96.5 & 82.42 \\
\hline $2017-1$ & 14.960 & 166.8 & 89.69 \\
\hline $2017-2$ & 12.972 & 165.2 & 78.52 \\
\hline $2018-1$ & 11.892 & 146.1 & 81.40 \\
\hline $2018-2$ & 18.095 & 167.0 & 108.37 \\
\hline $2019-1$ & 19.087 & 199.3 & 95.79 \\
\hline TOTAL & 111.705 & & \\
\hline
\end{tabular}

\section{Angola}

\begin{tabular}{|c|c|c|c|}
\hline SEÇÃO & FREQ & TAMANHO & POR MILHÃO \\
\hline $2012-1$ & 28 & 17.7 & 1.58 \\
\hline $2012-2$ & 21 & 19.7 & 1.06 \\
\hline $2013-1$ & 30 & 55.3 & 0.54 \\
\hline $2013-2$ & 21 & 60.1 & 0.35 \\
\hline $2014-1$ & 7 & 62.0 & 0.11 \\
\hline $2014-2$ & 19 & 65.7 & 0.29 \\
\hline $2015-1$ & 50 & 72.0 & 0.69 \\
\hline $2015-2$ & 65 & 76.0 & 0.86 \\
\hline $2016-1$ & 67 & 73.7 & 0.91 \\
\hline $2016-2$ & 80 & 96.5 & 0.83 \\
\hline $2017-1$ & 169 & 166.8 & 1.01 \\
\hline $2017-2$ & 201 & 165.2 & 1.22 \\
\hline
\end{tabular}




\begin{tabular}{|c|r|c|c|}
\hline SEÇÃO & FREQ & TAMANHO & POR MILHÃO \\
\hline $2018-1$ & 173 & 146.1 & 1.18 \\
\hline $2018-2$ & 43 & 167.0 & 0.26 \\
\hline $2019-1$ & 0 & 199.3 & 0.00 \\
\hline TOTAL & 974 & & \\
\hline
\end{tabular}

\section{Mozambique}

\begin{tabular}{|c|c|c|c|}
\hline SEÇÃO & FREQ & TAMANHO & POR MILHÃO \\
\hline $2012-1$ & 4 & 17.7 & 0.23 \\
\hline $2012-2$ & 33 & 19.7 & 1.67 \\
\hline $2013-1$ & 19 & 55.3 & 0.34 \\
\hline $2013-2$ & 44 & 60.1 & 0.73 \\
\hline $2014-1$ & 39 & 62.0 & 0.63 \\
\hline $2014-2$ & 50 & 65.7 & 0.76 \\
\hline $2015-1$ & 33 & 72.0 & 0.46 \\
\hline $2015-2$ & 10 & 76.0 & 0.13 \\
\hline $2016-1$ & 35 & 73.7 & 0.48 \\
\hline $2016-2$ & 34 & 96.5 & 0.35 \\
\hline $2017-1$ & 84 & 166.8 & 0.50 \\
\hline $2017-2$ & 92 & 165.2 & 0.56 \\
\hline $2018-1$ & 51 & 146.1 & 0.35 \\
\hline $2018-2$ & 20 & 167.0 & 0.12 \\
\hline $2019-1$ & 0 & 199.3 & 0.00 \\
\hline TOTAL & 548 & & \\
\hline & & & \\
\hline
\end{tabular}

\section{Irei+infinitivo en el contexto de expresión de la futuridad}

La forma irei+infinitivo es el resultado natural del proceso de gramaticalización de ciertas formas que expresan futuridad, concretamente de la temporalización de la perífrasis vou+infinitivo y de la modalización del futuro sintético amarei. La forma vou+infinitivo se define por una combinación de valores modales y epistémicos (grado de certeza e intencionalidad), temporales (futuridad inmediata o simplemente futuridad) y aspectuales (prospectivos, inminenciales e incoativos). Estos últimos contenidos aspectuales han remitido 
en todo el portugués, sobre todo en el de Brasil, provocando que en muchos casos la perífrasis ir+infinitivo se temporalice, expresando únicamente futuridad junto con los valores modales. Incluso en la variedad de Brasil, el uso casi exclusivo como forma de expresión de la futuridad de ir+infinitivo en la lengua oral y cada vez más en la lengua escrita provocaría que algunos de los valores modales ligados a esta forma perifrástica, como los de intención o de alto grado de compromiso, también se difuminen. El uso masivo de la forma vou+infinitivo con valor de futuridad sin valores aspectuales, tanto en la variedad del PB como en el PE, abriría la puerta a una nueva forma de futuro perifrástica: irei+infinitivo.

Por otra parte, la modalización de la forma sintética amarei, así como su reducción en contextos de uso en ambas variedades del portugués, pero más profusamente en $\mathrm{PB}$, habría dejado un espacio para una función de futuro distante, que antes desempeñaba el futuro sintético amarei frente a la perífrasis vou+infinitivo y que ahora experimenta la competencia de un tercer elemento, la forma irei+infinitivo que tiende a ocupar el espacio de la forma sintética como expresión de la futuridad distante y mediata. Así, esta nueva forma irei+infinitivo estaría definida por un contenido modal epistémico intencional y de compromiso del hablante con la acción futura y un contenido temporal de futuridad inmediata y mediata. Para el triunfo de esta forma convergen las tendencias naturales de la lengua, aceleradas en el PB, como la temporalización de la forma perifrástica vou+infinitivo y la modalización de la forma sintética amarei y un conjunto de condiciones sincrónicas que son asimismo decisivas para el éxito de esta forma. A saber:

La forma sintética provoca ciertos problemas combinatorios con los pronombres personales átonos en algunos contextos ${ }^{9}$ a los hablantes (mesoclisis) (8), solventables en la variante brasileña mediante la forma irei+infinitivo (9).

(8) Dir-te-ei a verdade / *Direi-te a verdade.

(9) Irei dizer-te a verdade/Irei te dizer a verdade ${ }^{\text {ro }}$.

\footnotetext{
9 Por ejemplo, después de pausa o al inicio de una oración.

Io Apenas se constatan casos de colocación mesoclítica ir-te-ei dizer. En PE, de la forma irei-te dizer se encuentran escasos casos, ceñidos a registros coloquiales mayoritariamente orales. Ya la forma del PB irei te dizer sin guion es habitual en el registro coloquial, puesto que al perderse el elemento de unión (traço de união) a partir del modelo de la perífrasis con el verbo ir en presente vou te dizer se reinterpreta que no se trata ya de una colocación mesoclítica porque el pronombre te aparece como un elemento aislado, independiente del verbo precedente.
} 
A diferencia de la forma sintética, por su condición de forma perifrástica, irei+infinitivo puede añadir un valor modal intencional y de mayor compromiso con la acción futura, ausente en la forma sintética, siendo, por ello, una forma propicia para textos formales no ceremoniosos (Io):

(เо) O prémio irá ser recolhido pelo seu filho (+compromiso +distancia temporal).

Frente a la forma perifrástica con el verbo ir en presente, irei+infinitivo sirve para aludir a un futuro más distante con menor compromiso por parte del hablante, pero con mayor formalidad. Irei+infinitivo proporciona, así, al hablante la distancia necesaria para no comprometerse con una acción futura sin distanciarse demasiado como con la forma sintética -rei y, a la vez, mantener su compromiso como con la forma perifrástica vou+infinitivo. Sería una forma equidistante entre el mayor compromiso de vou+infinitivo (II) y el menor compromiso de -rei (12). Irei+infinitivo sería una forma de compromiso para un futuro distante.

(II) O prémio vai ser recolhido pelo seu filho (+compromiso -distancia temporal).

(I2) O prémio será recolhido pelo seu filho (-compromiso +distancia temporal).

La forma sintética amarei es poco usada en la lengua oral excepto en discursos orales cultos o muy formales. En los textos escritos cultos sí se emplea la forma sintética. Esta nueva forma podría, y puede usarse, en textos escritos de un registro elevado o en discursos cultos orales. Esta forma surgiría como una necesidad de los hablantes para expresar futuro distante en textos orales cultos y escritos de menor formalidad mediante la forma perifrástica más usada ir+infinitivo.

Incluso para los malos usuarios de la lengua, entre ellos los traductores indolentes, la nueva pareja de formas perifrásticas para el futuro en portugués vou/irei+infinitivo podría adaptarse a los futuros perifrásticos del inglés I'am going to+infinitivo=vou+infinitivo y I will+infinitivo=irei+infinitivo. En este sentido, aunque parezca desmedido, ese parece ser el criterio seguido en muchos casos en la subtitulación de películas y teleseries de lengua inglesa original.

El crecimiento de las formas 'gerundistas' (ir)estar+gerúndio en la norma del PB para expresar un contenido modal epistémico de mayor compromiso del hablante con la acción futura. Este valor era desempeñado por la forma perifrástica ir+infinitivo frente la forma sintética -rei. Esta última suponía un menor compromiso y se empleaba para expresar más formalidad y mayor distancia con respecto al hecho futuro. El desuso de esta forma -rei y el uso 
de ir+infinitivo para cualquier tipo de futuridad ha incentivado el uso de estas formas de gerundio para ese valor de compromiso, abandonado parcialmente por la forma perifrástica vou+infinitivo. La forma irei+infinitivo, por su parte, ha recogido parte del valor de futuridad distante no comprometedora, si bien la misma forma perifrástica impone cierto contenido modal intencional y de compromiso que no tiene la forma sintética -rei.

Si el camino evolutivo continúa por esta senda, nos atrevemos a vaticinar que posiblemente la forma sintética amarei reducirá aún más su uso como expresión de la futuridad, llegando a poseer meramente valores modales, incluso en la norma escrita, empezando por el portugués de Brasil, donde la sustitución está en un estado más avanzado. La forma perifrástica irei+infinitivo ocupará el espacio que la forma sintética tenía en contraste con la forma perifrástica vou+infinitivo como expresión de la futuridad, sin ninguna conexión con el ME (independientemente de la distancia temporal), adquiriendo progresivamente los valores modales de la forma sintética amarei de futuridad distante y de menor compromiso del hablante. Además, la forma irei+infinitivo se irá extendiendo por todos los registros, tanto de la lengua oral como de la lengua escrita, cambiando así las relaciones temporales de expresión de la futuridad actuales.

\section{Bibliografía}

Barbosa, Juliana. 2007. A expressão do futuro no português brasileiro contemporâneo. Revista eletrônica do instituto de humanidades VI(XXIII), out-dez: 425I. Visto en http://publicacoes.unigranrio.edu.br/index.php /reihm/article/ view/60/64. [Acesso oI/06/2020]

Barroso, Henrique. I994. O aspecto verbal perifrástico em português contemporâneo: visão funcional/ sincrónica. Porto: Porto editora. [publicação (com correcções) do trabalho de síntese das provas de a.p.c.c.].

Bauhr, Gerhard. I989. El futuro en -ré e ir a + infinitivo en español peninsular moderno. Göteborg: Acta Universitatis Gothoburghensis.

Bechara, Evanildo. I999 [196r]. Moderna gramática portuguesa. 37. ed. revista e ampliada. Río de Janeiro: Lucerna.

Bravo, Ana. 2008. La perífrasis 'ir a+infinitivo' en el sistema temporal $y$ aspectual del español. Tesis Doctoral. Madrid: Universidad Complutense de Madrid. ISBN: 978-84-669-3192-2.

Bybee, Joan; Revere, Perkins \& Pagliuca, William. I994. The evolution of grammar: tense, aspect, and modality in the languages of the world. Chicago: University of Chicago press. 
Cunha, Celso \& Cintra, Luis Filipe.I984. Nova gramática do português contemporâneo. Lisboa: Edições João sá da costa.

Dos santos, Josete. 2004. Os verbos modais e uma análise do futuro. En III Jornada nacional de lingüística e filologia da língua portuguesa, Circulo fluminense de estudos filológicos e linguísticos, Brasil, novembro de 2008, 7-24. http://www. filologia.org.br/iiijnlflp [Accesso 03/06/2020].

Fidalgo, Francisco José. 20I2. La expresión de la futuridad en portugués y su contraste con el español. Tiempos verbales y formas perifrásticas. Tesis de doctorado. Salamanca: Universidad de Salamanca.

Fleischman, Suzanne. I982. The future in thought and language. diachronic evidence from romance. Cambridge: CUP.

GDP (Gramática do português) Raposo, Eduardo Buzaglo Paiva; Bacelar do Nascimento, Maria Fernanda; da Mota, Maria Antónia Coelho; Segura, Luísa \& Mendes, Amália. 2013. Gramática do Português. Vol. I e II. Lisboa: Fundação Calouste Gulbenkian.

Heine, Bernd; Ulrike, Claudi \& Hünnemeyer, Friederike. I991. Grammaticalization: a conceptual framework. Chicago: Chicago University press.

Klein, Wolfgang. I994. Time in Language. London: Routledge.

Longo, Beatriz. I998. Perífrases temporais no português falado. Veredas 2(2) jul/dez, 9-24.

Mateus, Maria Helena Mira; Brito, Ana Maria; Duarte, Inês; Hub Faria, Isabel; Frota, Sónia; Matos, Gabriela; Oliveira, Fátima; Vigário, Marina \& Villalva, Alina. 2003. Gramática da Língua Portuguesa. Lisboa: Editorial Caminho.

Melis, Chantal. 2006. Verbos de movimiento. La formación de los futuros perifrásticos. En Sintaxis histórica de la lengua española. Primera parte: la frase verbal. Concepción Company (dir.). México: UNAM-FCE, 873-968.

Oliveira, Fátima. I985. O futuro em português: alguns aspectos temporais e/ou modais. En Actas do $1^{\circ}$ encontro da Associação Portuguesa de Linguística. Lisboa: Associação Portuguesa de Linguística, 353-373.

Oliveira, Josane. 2006. O futuro da língua portuguesa ontem e hoje: variação e mudança. Tese (doutorado em letras). Rio de Janeiro: Faculdade de letras, Universidade Federal do Rio de Janeiro.

Oliveira, Josane \& Olinda, Sílvia. 2008. A trajetória do futuro perifrástico na língua portuguesa: séculos xviı, xix e xx. Revista da Abralin 7(2), jul./dez: 93-II7. http://www.abralin.org/revista/rv7n2/o4-josane-moreira-e-silviarita\%5bi\%5d.pdf. [Acceso 04/06/2020].

Poplack, Shana \& Malvar, Elisabete. 2007. Elucidating the transition period in linguistic change. Probus I9: I2I-I69. DOI I0.I5I5/PROBUS.2007.005

Tafner, Elisabeth. 2004. As formas verbais de futuridade em sessões plenárias: uma abordagem sociofuncionalista. Dissertação (mestrado em Linguística). Florianópolis: Faculdade de Letras, Universidade Federal de Santa Catarina.

Thomas, Earl.ig69. The syntax of spoken Brazilian Portuguese. Nashville: Vanderbilt University. 
Santos, A. M. I997. O futuro verbal no português do Brasil em variação. Dissertação de mestrado. Brasília: UNB.

Vilela, Mário. I999. Gramática da língua portuguesa. Coimbra: Livraria Almedina.

Vázquez Cuesta, Pilar \& Mendes da Luz, Maria Albertina. I97I. Gramática portuguesa. (3. ${ }^{a}$ edición). Madrid: Gredos. 
